|| Print ISSN: 2589-7837 || Online ISSN: 2581-3935 ||

International Journal of Medical Science and Diagnosis Research (IJMSDR)

Available Online at www.ijmsdr.com

NLM (National Library of Medicine ID: 101738824)

Review Article

Volume 5, Issue 11; November:2021; Page No. 25-37

\title{
CAD/CAM in Restorative Dentistry
}

\section{Dr. Anil K Tomer ${ }^{1}$, Dr. Ayan Guin ${ }^{2}$, Dr. Shivangi Jain ${ }^{3}$, Dr. Geetika Sabharwal', Dr. Nivedita Saini ${ }^{5}$}
${ }^{1}$ Professor and Head, Department of Conservative Dentistry and Endodontics, Divya Jyoti College of Dental Sciences and Research, Modinagar, Uttar Pradesh.

${ }^{2-5}$ Postgraduate students, Department of Conservative Dentistry and Endodontics, Divya Jyoti College of Dental Sciences and Research, Modinagar, Uttar Pradesh.

Conflicts of Interest: Nil

Corresponding author: Dr. Ayan Guin

DOI: https://doi.org/10.32553/ijmsdr.v5i11.880

\begin{abstract}
:
Computers have had a huge impact on the dental place of work and dental exercise major to huge adjustments in communication, financial accounting, and administrative functions. Computerized systems have greater currently generated developing variety of software program for the delivery of affected character treatment. Digital effect systems and chairside CAD/CAM systems offer opportunities to mix virtual impressions and entire contour restorations withinside the dental place of work. Systems depend on single picturegraph and video cameras to report the digital file that is the foundation for an accurate outcome. This article gives key elements of automatic generation using the CAD/CAM process. CAD/CAM technique appears to be the most common technique currently available; this is fast, easy and maintains time. CAD/CAM systems are variable; therefore, using the right gadget with a logical approach for treating patients are quite mandatory.
\end{abstract}

Keywords: CAD/CAM systems

\section{Introduction:}

Computers have had a full-size impact on the dental administrative center and dental exercise essential to tremendous changes in communication, financial accounting, and administrative functions. Computerized systems have more lately generated developing style of software program for the transport of affected person treatment. Computerized Dentistry and Digital Dentistry are terms that have been used to give an explanation for the medical utility of Computer Assisted Design, Computer Assisted Machining (CAD/CAM). CAD/CAM systems are observed in every dental laboratories and dental workplaces as every docs and laboratory technicians work to discover the advantages and limitations of these systems. There are 3 preferred strategies involved with the CAD/CAM workflow. ${ }^{1}$ The first technique is to report the geometry of the patient's dentition and smooth tissues to a computer. More recently, intraoral scanners or cameras were introduced that permit dentists the possibility to do the scanning technique without the want for traditional impressions and stone models. The 2nd technique includes usage of the scanned facts in a CAD software program software. The software is applied to endorse a quantity version of the preferred prosthesis at the digital version of the dentition. Additional software program enhancing gear permit for personalization of the recovery unique to the wishes of the case. And the third technique is to make use of the virtual notion of the prosthesis to direct a machining tool to manufacture the preferred outcome. Currently 
marketed structures are usually divided into wide categories. Digital affect structures awareness at the imaging system and rely upon dental laboratories to finish the layout and fabrication techniques, and chair side $\mathrm{CAD} / \mathrm{CAM}$ structures awareness on integrating all 3 techniques with inside the dental office. As dentistry evolves into the virtual global of photograph capture, laptop design, and the introduction of dental restorations via robotics, the dental laboratory ought to evolve as well. Computer-aided design/Computer-aided manufacturing $(\mathrm{CAD} / \mathrm{CAM})$ restoration offers us that option. ${ }^{2}$

\section{Evolution of CAD-CAM systems:}

Computer-aided layout and production had been evolved withinside the 1960s for the use withinside the plane and automotive industries. Dr. Francosis Duret became the primary person to broaden $\mathrm{CAD} / \mathrm{CAM}$ device, making crowns primarily based totally on an optical affect of the abutment tooth and the use of a numerically managed milling gadget in 1971 . He produced the primary CAD/CAM dental recovery in 1983 (4). Dr. Andersson evolved the Procera Method of producing high-precision dental crowns in 1983. Dr. Duret later evolved the Sopha machine in
1984(4). Dr. Andersson became the primary man or woman to apply CAD/CAM for composite veneered restorations(5). The E4D Dentist machine, which became delivered in 2008 allows same-day in-workplace restorations together with CEREC machine. ${ }^{3}$

\section{CAD-CAM components:}

Scanner: They are basically two types: a) optical scanners b) mechanical scanners

Optical scanner: The basis of this kind of scanner is the gathering of third-dimensional systems in a so-called 'triangulation procedure'. Here, the supply of light (eg. laser) and the receptor unit are in a specific perspective of their courting to one another. Through this perspective the pc can calculate a third-dimensional information set from the picture at the receptor unit ${ }^{4}$. Either white light projections or a laser beam can function a supply of illumination. The following may be named as examples of optical scanners at the dental market:

- Lava Scanner (3M ESPE, white light projections).

- Everest Scan (KaVo, white light projections).

- es1 (etkon, laser beam ).

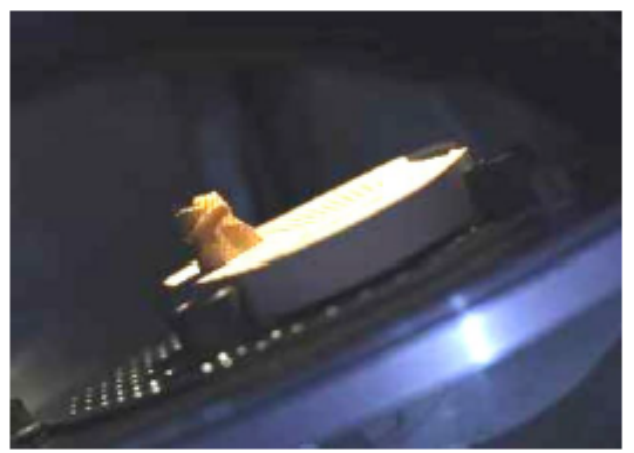

Fig 1 : Optical scanner Of CAD/CAM System

Mechanical Scanner: In this scanner variant, the draw close forged is observe robotically line-vialine via method of a ruby ball and the thirddimensional form measured. The Procera Scanner of Nobel Biocare (Göteborg) is the maximum most effective example for mechanical scanners in cutting-edge dentistry. This form of scanner is outstanding via a immoderate scanning accuracy, in which the diameter of the ruby ball is ready to the smallest grinder withinside the milling gadget, with the stop end result that all facts collected via the gadget additionally may be milled. ${ }^{5}$ The drawbacks of this facts measurement method are to be seen withinside the inordinately complicated mechanics, which make the system very steeplypriced with prolonged processing times in evaluation to optical. 


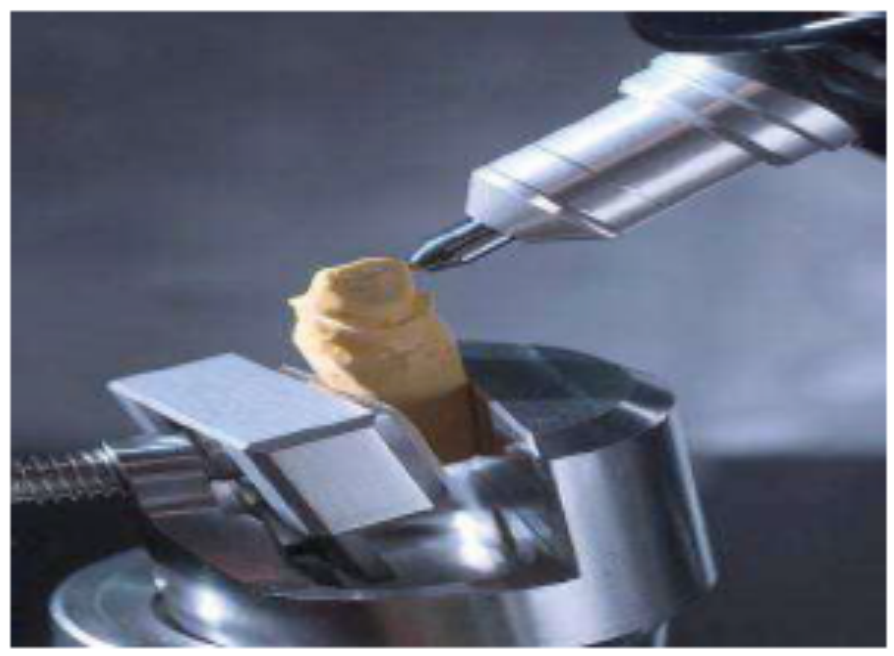

Fig 2 : Mechanical scanner Of CAD/CAM System

\section{Design software:}

Special software program is furnished via way of the producers for the layout of numerous types of dental restorations. With such software program, crown and fixed partial dentures (FPD) frameworks may be built on the only hand on the alternative hand, a few structures additionally provide the layout of full crowns, half crowns, inlays, inlay with FPDs, and telescopic primary crowns.

The software program of CAD/CAM structures currently to be had available in the marketplace is being constantly improved. The cutting-edge production opportunities are constantly to be had to the consumer by using updates. The facts of the development may be saved in numerous facts formats. The foundation consequently is frequently fashionable transformation language (STL) facts. Many producers, however, use their very own facts formats, unique to that precise manufacturer, with the end result that facts of the construction packages aren't well suited with every other. $^{4}$
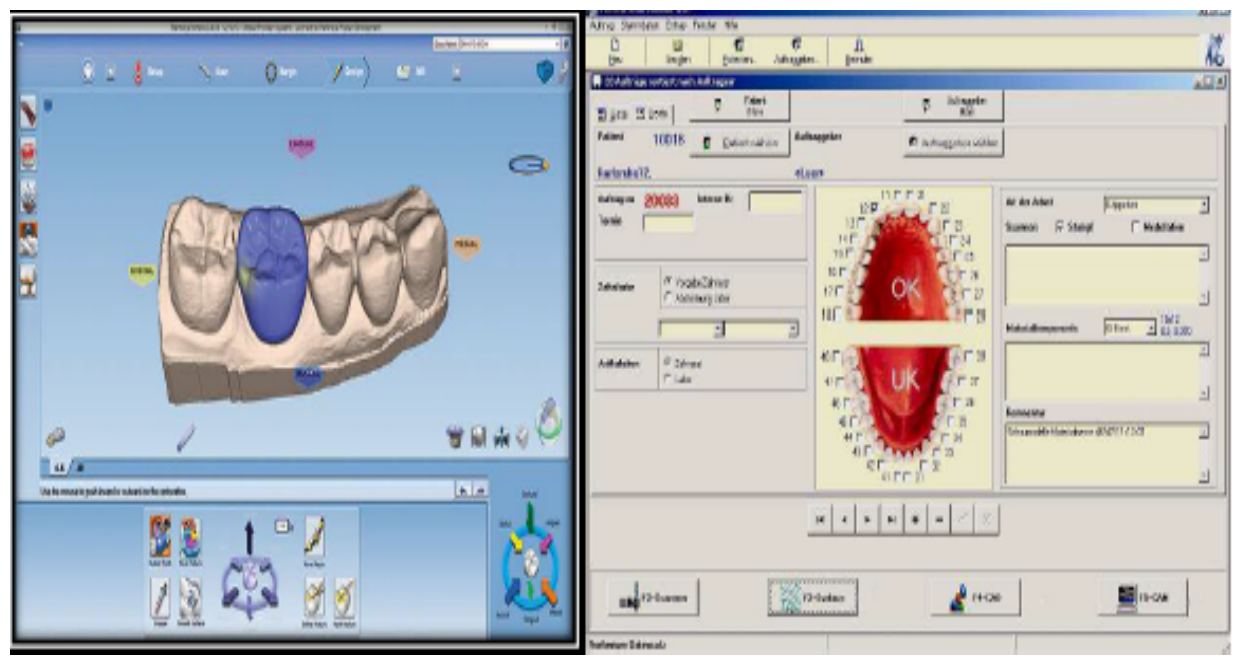

Fig 3 : CAD Software /For Dental prosthesis Design 


\section{Processing devices :}

The production records produced with the CAD software program are transformed into milling strips for the CAM-processing and sooner or later loaded into the milling device. Processing gadgets are outstanding with the aid of the range of milling axes. ${ }^{6}$

- 3-axis devices.

- 4-axis devices.

- 5-axis devices.

\section{General Classification Of CAD/CAM Systems:}

Based on their manufacturing techniques structures had been divided into the following :

1. In office machine: Most extensively used is Cerec System. Intraorally scanning of the instruction and choice of suitable substances is performed with the aid of using this machine because of which the restorations may be fabricated and seated inside a single appointment.

2. CAD/CAM- Dental laboratory systems: The oblique systems take a look at a dental stone forged or die of the prepared tooth, with in the dental lab (eg Cerec-in lab). Many of these systems produce copings after which the dental technician affords esthetic porcelain to the restoration.

3. CAD/CAM the usage of networks for outsourcing dental lab work: Technologies the usage of $\mathrm{CAD} / \mathrm{CAM}$ with community machining center because of this outsourcing the framework fabrication the usage of an internet have been delivered due to the fact the format and fabrication of the framework for immoderate electricity ceramics is approach sensitive. $^{6}$

\section{Most Common CAD/CAM Systems:} Cercon:

It does now no longer have a CAD component. In this gadget, a wax sample (coping and pontic) with a minimal thickness of $0.4 \mathrm{~mm}$ is made. The gadget scans the wax sample and mills a zirconia bridge coping from presintered zirconia blanks. The coping is then sintered withinside the Cercon warmness furnace $(1,350 \mathrm{C})$ for 6 to 8 hours. $^{7}$

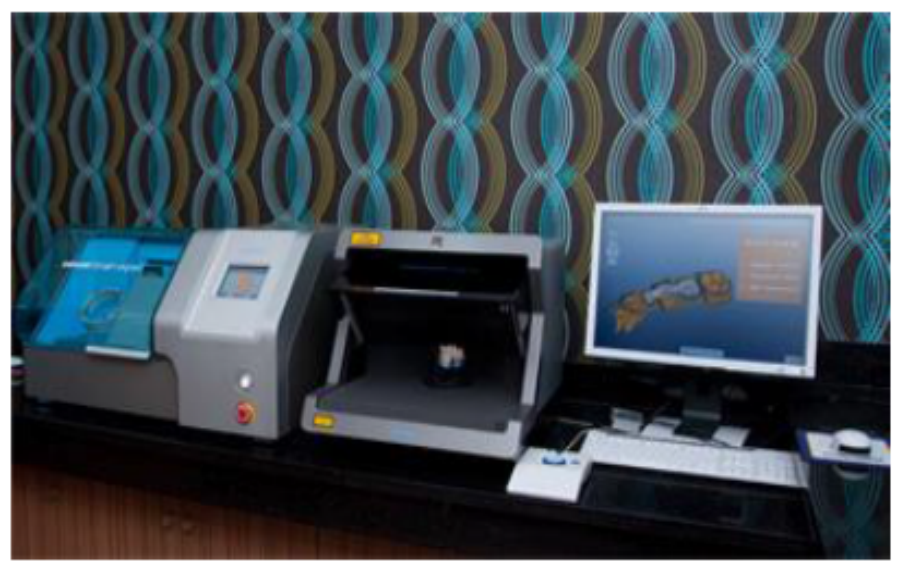

Fig 4 : Cercon System

\section{Everest:}

The Everest gadget includes scan, engine, and therm components. In the scanning unit, areflection loose gypsum solid is constant to the turntable and scanned with the aid of using a CCD digital digicam in a 1:1 ratio with an accuracy of dimension of $20 \mu \mathrm{m}$. Its machining unit has 5-axis motion this is able to generating detailed morphology and unique margins from quite a few materials. Examples: leucite bolstered glass ceramics, partly and completely sintered zirconia, and titanium 

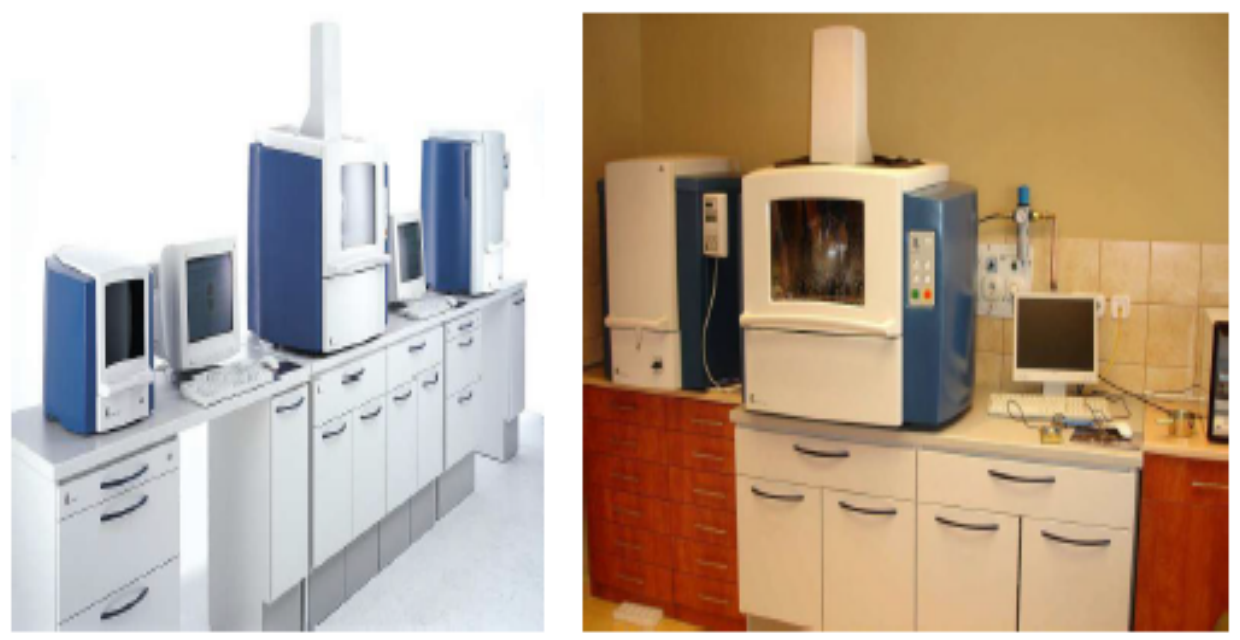

Fig 5 : Everest In Lab Of CAD/CAM System

\section{Lava:}

This gadget makes use of yttria stabilized tetragonal zirconia poly crystals (Y-TZP) that have more fracture resistance than traditional ceramics.Lava gadget makes use of a laser optical gadget to digitize The Lava CAD software program robotically reveals the margin and indicates a pontic. The framework is designed to be $20 \%$ large to make amends for sintering shrinkage. ${ }^{7}$

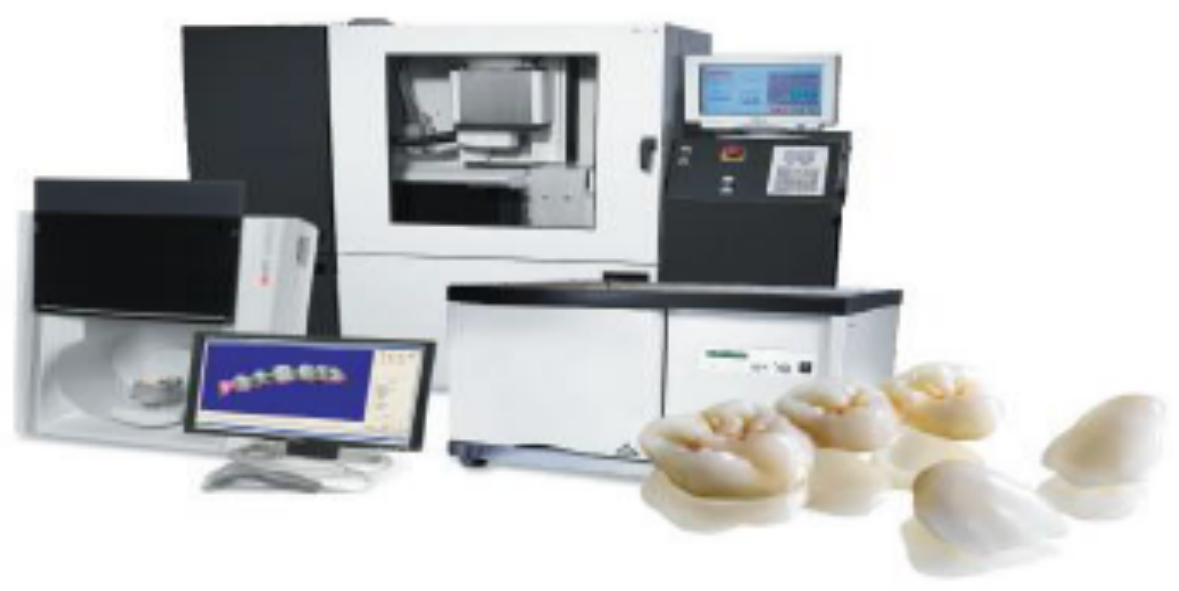

Fig 6 : Lava CAD/CAM System

\section{Procera:}

This system has blended pantographic duplicate with electric discharge (spark erosion) machining. It makes use of an progressive idea for producing its alumina and zirconia copings. First, a scanning stylus acquires 3-D pictures of the grasp dies which might be despatched to the processing middle through modem. The processing middle then generates enlarged dies designed to atone for the shrinkage of the ceramic material. Copings are synthetic with the aid of using dry urgent highpurity alumina powder $(>99.9 \%)$ in opposition to the enlarged dies. These compact packed copings are then milled to the actual thickness. The Procera restorations have incredible medical toughness and strength. ${ }^{8}$ 

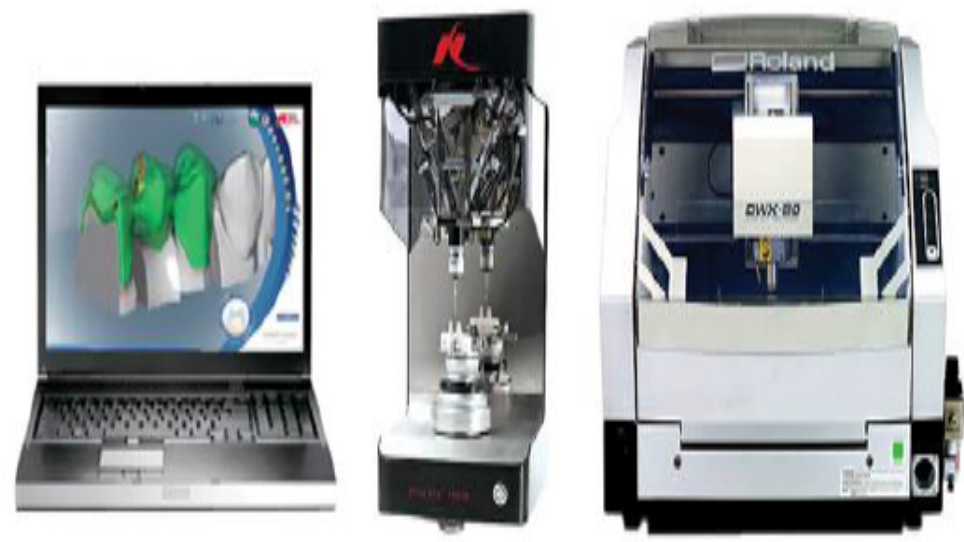

Fig 7 : Procera CAD CAM system

\section{DCS Precident:}

It is constructed from a Preciscan laser scanner and Precimill CAM multitool milling center. It can experiment 14 dies simultaneously and mill as much as 30 framework devices in 1 absolutely automated operation. Materials are used: Porcelain, Ceramic glass, Dense Zirconia, metals, and Fiber- Reinforced Composites. This machine is one of the few CAD/CAM structures which could mill titaniumand absolutely dense sintered zirconia. $^{8}$

\section{CICERO System:}

The laptop included crown reconstruction become evolved with the aid of using CICERO Dental System B.V. (Hoorn, The Netherlands). The
CICERO technique for manufacturing of ceramic restorations makes use of reliable scanning, ceramic sintering, and laptop assisted milling strategies to manufacture restorations with maximal static and dynamic occlusal touch relations. The device uses optical scanning, close to net-formed metal, ceramic sintering and laptopaided fabrication strategies. ${ }^{9}$

\section{CEREC SYSTEM:}

The computer- aided design/computer-aided manufacture (CAD/CAM) CEREC (computerassisted CERamic REConstruction) machine is used for electronically designing and milling restorations. ${ }^{10}$

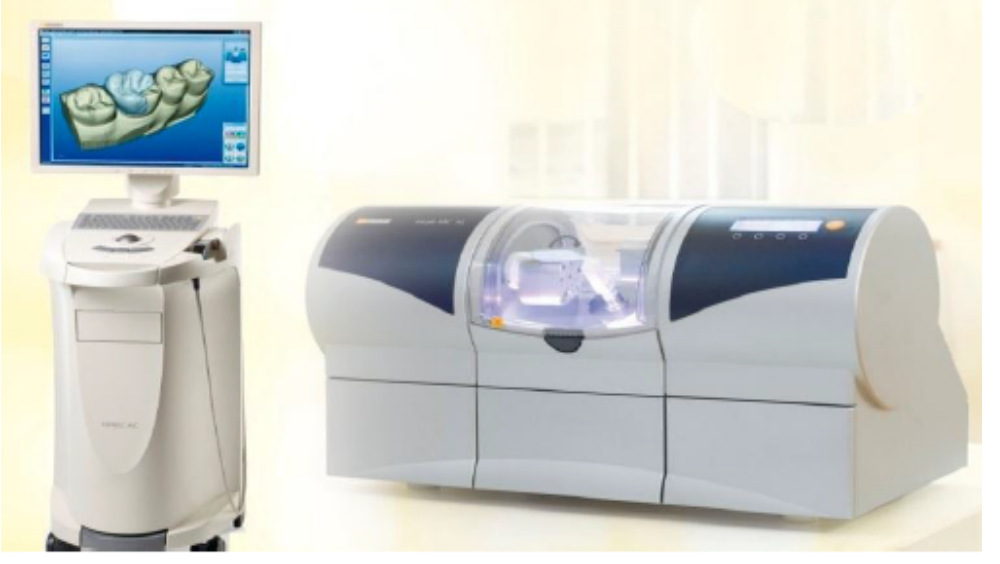

Fig 8 : CEREC CAD CAM system 


\section{CEREC in Lab:}

Is a laboratory device wherein operating except a laser-scanned and a virtual photo of the digital version is displayed on a screen. After designing the coping or framework, the laboratory technician puts an appropriate VITA In-Ceram block into the CEREC in Lab system which causes milling. The technician then verifies the healthy of the milled coping or framework. ${ }^{8}$

E4D Dentist System:

Presently it's far the most effective machine except CEREC that allows equal day in-workplace restorations. This machine consists of a laser scanner (Intraoral digitizer), a layout middle and a milling unit. The scanner is positioned close to the goal tooth, and has 2 rubber toes that preserve it to precise distance from the region being scanned. As every photo is taken, the software program step by step creates a three-D image. The layout machine mechanically detects the end strains and marks them at the screen. As quickly because the recovery is approved, the facts are transmitted to both the in-residence milling device or a dental laboratory. The workplace milling device will then manufacture the recovery from the selected blocks of ceramic or composite. ${ }^{11}$

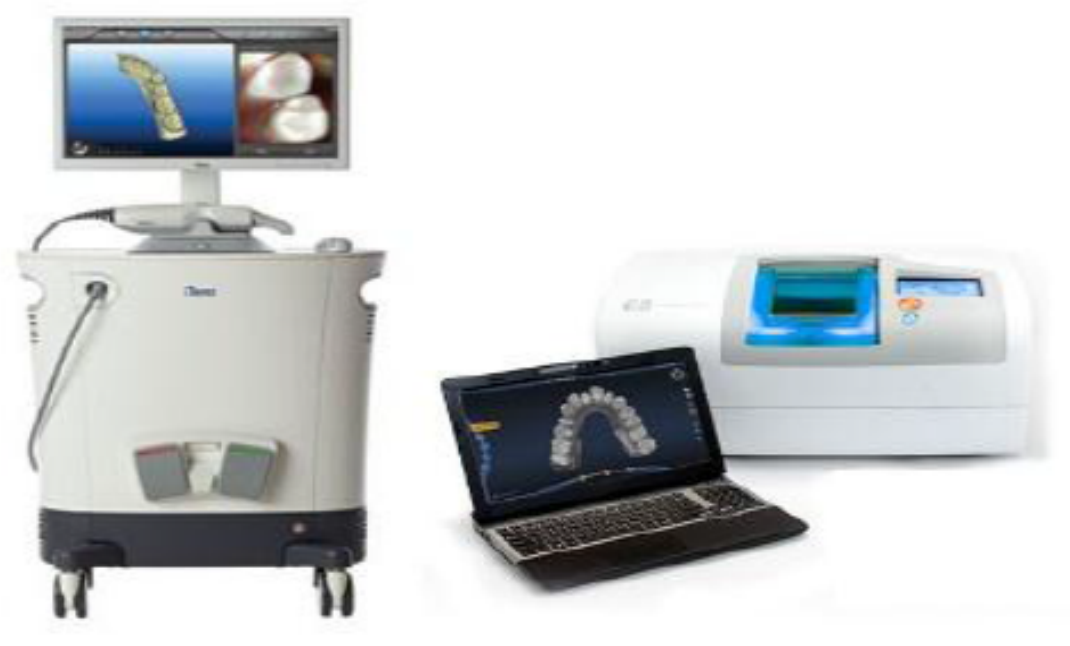

Fig 9 : E4D System Of CAD/CAM

The iTero, E4D, and TRIOS cameras are single picture cameras. The TRIOS digital digicam information photographs at this kind of fast fee that it procedures the functional look of a video digital digicam. About 3 teeth can generally be covered in a single picture. To file large regions of the dentition, a chain of overlapping character photographs are recorded that the software program software can collect right into a large 3dimensional digital version. The digital digicam is positioned via exceptional angles to make sure correct recording of information under the peak of contour that could be hidden from the digital digicam if handiest an occlusal view changed into obtained. Those regions now no longer visualized through the digital digicam withinside the overlapping photographs could then be extrapolated through the software program software to fill withinside the lacking information regions withinside the digital version. Calculated regions of the information are handiest appropriate in regions of the digital version that could now no longer adversely have an effect on the very last recuperation such as proximal regions distant from the organized tooth. 


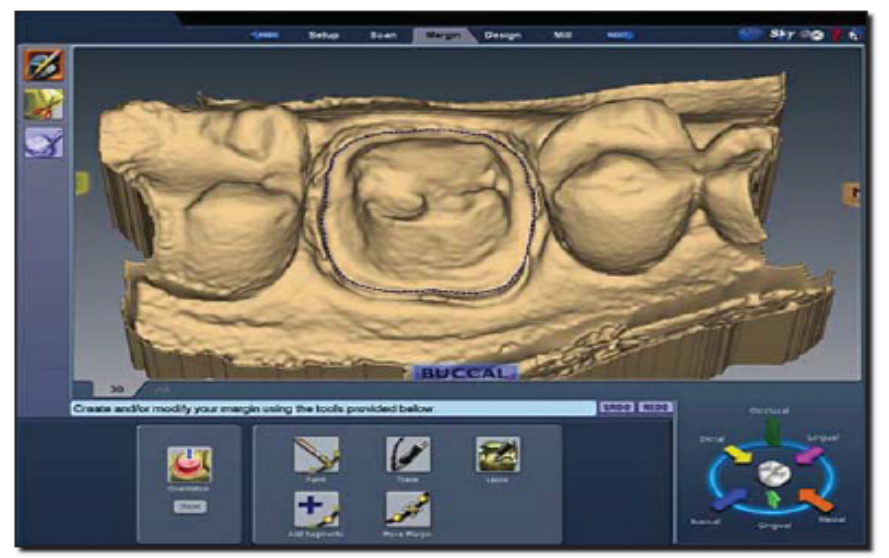

Fig 10 : Note areas of inconsequential missing scanned data extrapolated by the E4D software program in the cervical aspects of the teeth adjacent to the prepared tooth.

\section{Materials to be had for the use with CAD CAM} :

Almost all sorts of fixed (crowns, bridges, implant abutments, inlays and onlays) and detachable (detachable partial dentures) dental restorations further to orthodontic home equipment may be built the usage of CAD CAM technology. Different CAD CAM structures are well matched with unique sorts of substances. Silica-primarily based totally ceramics, infiltrated ceramics and oxide excessive overall performance ceramics (Aluminum Oxide and Yttrium stabilized Zirconium Oxide) are the most 14 broadly used substances with CAD CAM technology. ${ }^{6}$ The substances are to be had in blocks and are both mono-chromatic or poly chromatic. In addition to ceramics, metals (titanium, titanium alloys and chrome cobalt alloys), waxes and resin substances can be used with dental CAD CAM structures.

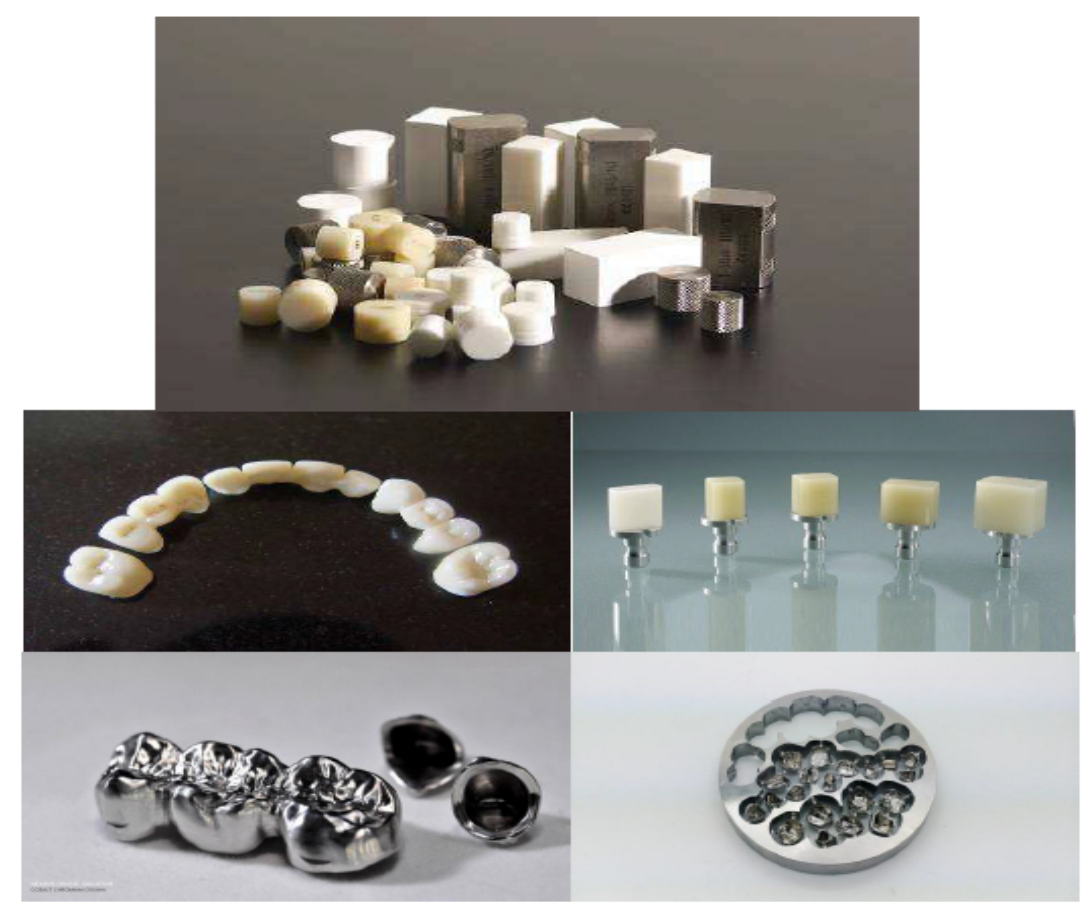

Fig 11 : materials used in CAD CAM system. 
Table 1 : Common Restorative Materials for Dental CAD/CAM Systems

\begin{tabular}{|l|l|l|l|}
\hline $\begin{array}{l}\text { Restorative } \\
\text { material }\end{array}$ & CAD/CAM system & Indications & Cementation \\
\hline Dicor MCG & Cerec & Inlay, onlay veneer & Adhesive(dual-cured) \\
\hline Vita Mark II & Cerec & Inlay,onlay,veneer,anterior crown & Adhesive(dual-cured) \\
\hline Pro CAD & Cerec & Inlay,onlay,veneer,anterior crown & Adhesive(dual-cured) \\
\hline In-Ceram Spinell & Cerec 3D, Cerec inLab & Anterior crown & $\begin{array}{l}\text { Adhesive(self } \\
\text { cured),conventional }\end{array}$ \\
\hline $\begin{array}{l}\text { In-Ceram Alumina } \\
\text { In-Ceram Zirconia }\end{array}$ & $\begin{array}{l}\text { Cerec 3D, Cerec inLab, 3D Cerec inLab, } \\
\text { DCS Precident }\end{array}$ & Crown and anterior bridge & $\begin{array}{l}\text { Adhesive(self- } \\
\text { cured),conventional }\end{array}$ \\
\hline $\begin{array}{l}\text { Alumina } \\
\text { DCrident } \\
\text { sintered Zir- } \\
\text { conia }\end{array}$ & $\begin{array}{l}\text { Procera } \\
\text { Procera,Everest, } \\
\text { Cercon }\end{array}$ & $\begin{array}{l}\text { Adhesive(self- } \\
\text { cured),conventional }\end{array}$ \\
\hline
\end{tabular}

\section{Stages in fabrication of prosthesis with CAD/CAM technology}

1. Computer floor digitization

2. Computer-aided designing

3. Computer assisted manufacturing

4. Computer-aided esthetics

5. Computer-aided finishing The ultimate levels are greater complicated and are nevertheless being evolved for inclusion in business systems. ${ }^{10}$

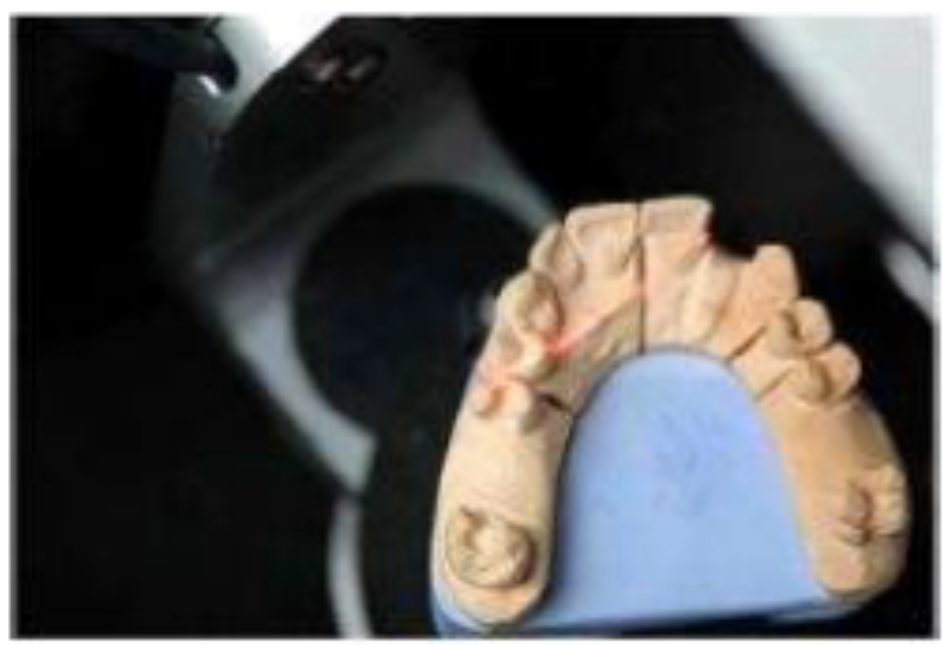

Fig 12 : Laser Based scanner 


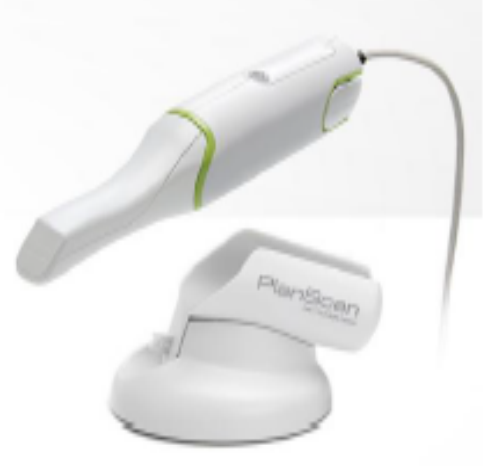

$A$

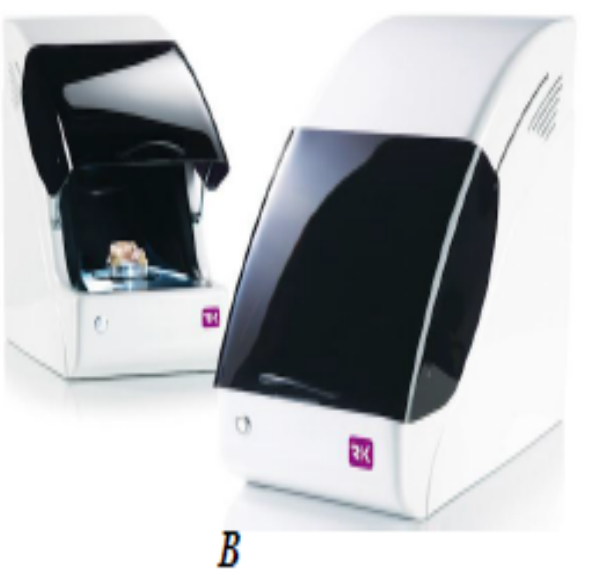

Fig 13 : A -intra oral B-extra oral scanners
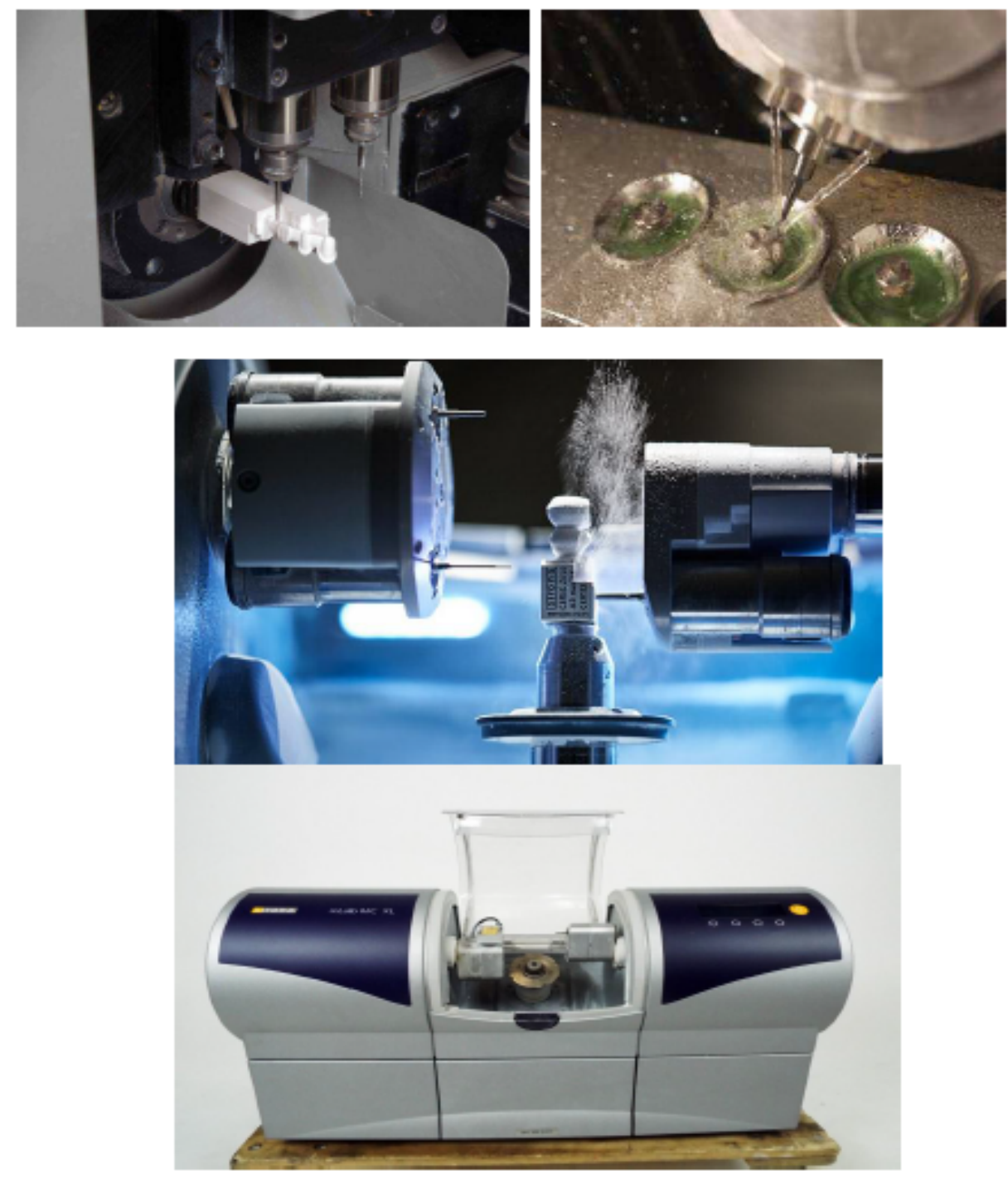

Fig 13 : CAD CAM milling process 
Advantages And Disadvantages Of CAD/CAM Technology :

Advantages

1. Applications of recent substances - High strength ceramics which are predicted to be the brand new substances for FPDs frameworks had been hard to manner the use of traditional dental laboratory technologies. Therefore, this challenged to use CAD/CAM processing. Due to a hit use of all-ceramic crowns, all ceramic structures have come to be a possible remedy options. ${ }^{12}$

2. Time effectiveness.

3 . Reduced laboratory.

4. Quality control.

5. Patients frequently revel in inflammation in, sensitivity in and/or trouble in cleansing temporized teeth. With this gadget temporaries come to be obsolete, for this reason making uncomfortable and unaesthetic transition instances a issue of past. Also, there's faded hazard of bacterial invasion for the duration of this phase, reduced pulpal pressure as a consequence of immoderate cleansing, drying or trauma, and reduced want for the extra enamel manipulation. ${ }^{1}$

6. It isn't always continually feasible for the dentist to create a complete arch of exactly parallel preparations. The laptop can calculate, design, and construct the copings, which may be cemented to yield a well-seating bridge.

7. Scanning an photo and viewing it on a laptop display screen lets in the dentist to study the coaching and affect, and make instant modifications to the coaching and/or retake the affect if necessary, previous to its being despatched to the milling unit or a laboratory. This guarantees no calls from a laboratory that the affect is defective. This review, in addition to seeing a coaching a couple of instances its ordinary length on a display screen, can bring about progressed preparations.

8. A virtual affect additionally method that sufferers do now no longer should have affect cloth and trays used, saving them discomfort. ${ }^{13}$
9. Latest innovation in $\mathrm{CAD} / \mathrm{CAM}$ gadget lets in occlusion to be regarded and evolved in dynamic state.

Disadvantages:

1. The number one attention in a CAD/CAM buy is the duration of the studying curve, which can also additionally variety from some days to numerous months and can bring about the lack of workplace manufacturing and lack of affected person remedy time. ${ }^{14}$

2. Other essential hassle is the capability for the dental crew to withstand the gadget"s use and the clinician"s loss of self belief in the usage of a automated gadget.

3. Capital prices of those structures are pretty excessive and speedy huge scale manufacturing of appropriate best recovery is essential to attain monetary viability. ${ }^{12}$

4. Matching the affected person"s teeth coloration to the blocks of substances used to manufacture the restorations may be a project to the dentist initially.

5. Some $\mathrm{CAD} / \mathrm{CAM}$ gadget is based on margin seize for digitization, consequently making subgingival margin seize challenging. ${ }^{14}$

6. $\mathrm{CAD} / \mathrm{CAM}$ is ever advancing era. Upgrades and updates are to be expected. The current software program takes no time to turn out to be obsolete. It is sensible to impeach how lengthy the era has been available in the marketplace and the way quickly a revision turns into available. Thus, the dentist can also additionally want to finances for month-to-month prices for technical guide and software program up gradation. ${ }^{14}$

\section{Significance for the dentist :}

In current years, the usage of CAD/CAM era has specially strongly prompted dental-technical manufacturing procedures. If one ignores chairside prostheses, the importance of this era for the dentist isn't at once clear. In current years, CAD/CAM manufacturing has without a doubt improved the palette of substances for dental 
prostheses via way of means of supplying get right of entry to to new ceramic substances with excessive dependability. ${ }^{15}$ The balance values of zirconium oxide ceramics permit, in lots of regions of indication, the usage of this fabric as an opportunity to metallic frames for everlasting prostheses. $^{16}$
On the idea of present knowledge, a tapered angle of among $4^{\circ}$ to $10^{\circ}$ is recommended. Subsections and irregularities at the floor of the organized teeth in addition to the 'introduction of troughs' with a opposite bevel coaching margin may be inadequately diagnosed through many scanners. ${ }^{16}$

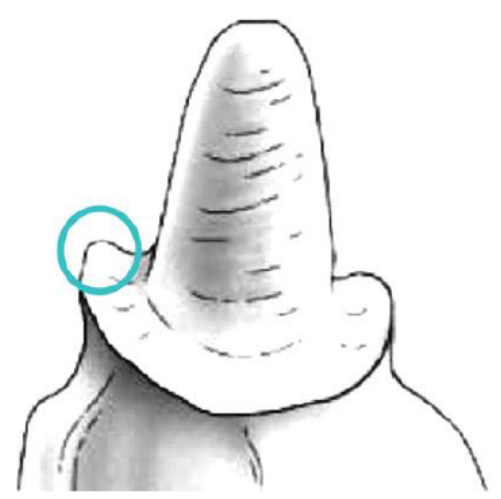

Fig 14 : Revers bevel preparation Making The preparation Hardly Detectable By The CAD/CAM

Moreover sharp incisor and occlusal edges are made rounded. Sharp and thinly extending edges in addition to $90^{\circ}$ shoulders in a ceramic recovery can bring about a awareness of tension; similarly sharp edges can't be milled precisely the usage of rounded grinders with inside the milling device. The diameter of the smallest grinder is $1 \mathrm{~mm}$ in maximum systems, so systems smaller than $1 \mathrm{~mm}$ can't be milled precisely. The end result is an misguided fit. ${ }^{16}$ A 360 degree shoulder or chamfer preparation is taken into consideration to be an appropriate marginal coaching geometries for $\mathrm{CAD} / \mathrm{CAM}$ produced all-ceramic restorations. In the case of FPDs, the abutment tooth can't display any divergence.

Future implications of CAD/CAM technology : In the future, ultrasound impressions could be applied the usage of ultrasonic waves, that have the functionality to penetrate the gingiva noninvasively with out retraction cords and now no longer be stricken by saliva, sulcular fluid, and blood. This will cause decisive advancements, as distinct cleansing and drying of the oral hollow space and related enamel shape becomes unnecessary, in addition to decreasing remedy time and growing affected person consolation in comparison with optical impressions. ${ }^{17}$

\section{Conclusion :}

There aren't anyt any doubts that treatment technology and substances in dentistry have regularly superior during the last 50 years, in particular withinside the discipline of restorative dentistry and prosthodontics. CAD/CAM structures have stepped forward very swiftly withinside the beyond 25 years, wherein quite a few structures has been released into the market. It may be used for more than one functions in dentistry. It is anticipated that CAD/CAM will go through in addition improvement withinside the close to destiny decades.

The evolution of evolved variations will deliver higher quality, extremely good cappotential and growth paintings manner friendliness. Materials might be to be had with excessive mechanical and bodily homes including higher esthetic, marginal integrity, put on resistance, and excessive power which allow ultimate for an extended length with inside the oral environment. Additionally, dental $\mathrm{CAD} / \mathrm{CAM}$ will also be to be had in instructional settings and as training equipment for every day 
dental practice, with explanatory substances for patients, diagnostic substances, and for simulations of surgical procedures.

\section{References:}

1. Beuer F, Schweiger J, Edelhoff D. Digital dentistry: An overview of recent developments for CAD/CAM generated restorations. Br Dent J 2008;204:505-511.

2. Lee C, Alex T. CAD/CAM Dentistry: A new forum for dentist-technician Teamwork. Inside Dentistry, Sep 2006: 2(7).

3. Davidowitz G., et al. "The use of CAD/CAM in dentistry". Dental Clinics of North America ,2011; 55(3): 559-570.

4. Mehl A, Gloger W, Kunzelmann K H, Hickel R. A new optical 3-D device for the detection of wear. J Dent Res, 1997; 76: 1799-1807.

5. Webber B, McDonald A, Knowles J. An in vitro study of the compressive load atfracture of Procera AllCeram crowns with varying thickness of veneer porcelain.J Prosthet Dent ,2003; 89: 154-160.

6. F. Beuer, J. Schweiger \& D. Edelho. Digital dentistry: an overview of recent developments for CAD/CAM generated restorations .British Dental Journal, 2008; 204, 505-511.

7. Mantri, S, Bhasin, „Cad/Cam In Dental Restorations: An Overview ${ }^{\text {ee Annals and }}$ Essences of Dentistry. , 2010; vol II(3): 12328.

8. Perng-Ru Liu. "A panorama of dental $\mathrm{CAD} / \mathrm{CAM}$ restorative systems. Compendium , 2005: 507-513.

9. Aeran H., et al. "Computer Aided DesigningComputer Aided Milling in Prosthodontics: A Promising Technology for Future".IJSS Case Reports and Reviews, 2014; 23-27.
10. Madhuri Patil1, Sharanappa Kambale, Amol Patil , Karishma Mujawar. Digitalization in Dentistry: CAD/CAM - A Review". Acta Scientific Dental Sciences ,2018; 2(1): 12-16.

11. Griggs J. "Recent Advances in Materials for All-Ceramic Restorations".Dental Clinics of North America, 2007; 51(3): 713-727.

12. Aalap Prajapati, Anchal Prajapati, Dhawal R.Mody, Anuraag B.Choudhary. Dentistry Goes Digital: A Cad-Cam Way- A Review Article,2014;13 (8): 53-59.

13. Prajapati A., et al. "Dentistry Goes Digital: A Cad-Cam Way- A Review Article". IOSR Journal of Dental and Medical Sciences,2014; 13(8) : 53-59.

14. Takashi M, Yasuhiro H, Jun K, Soichi K. A review of dental CAD/CAM: current status and future perspectives from 20 years of experience. Dental Materials Journal, 2009: 28(1): 44-56.

15. Sailer I, Feher A, Filser F, Gauckler L J et al. Five year clinical results of zirconia frameworks for posterior fixed partial dentures. Int J Prosthodont , 2007; 20: 383388.

16. Vult von Steyern P, Carlson P, Nilner K. Allceramic fixed partial dentures designed according to the DC-Zirkon technique. A 2year clinical study. J Oral Rehabil, 2005; 32: 180-187.

17. Vollborn T, Habor D, Pekam FC, Heger S, Marotti J, Reich S, et al. Soft tissue-preserving computer-aided impression: a novel concept using ultrasonic 3D-scanning. Int $\mathrm{J}$ Comput Dent 2014; 17(4): 277-96. 